\title{
USO DE ESTERCO BOVINO E DE AVES NA ADUBAÇÃO ORGÂNICA DA ALFACE COMO PRÁTICA AGROECOLÓGICA
}

\author{
Luis Eduardo Vieira Pinto ${ }^{1}$, Ezequiel Dias Gomes ${ }^{2}$, Thadeu Henrique Novais Spósito ${ }^{3}$. \\ ${ }^{1}$ Universidade do Oeste Paulista - UNOESTE, Programa de Pós-Graduação em Agronomia, Presidente \\ Prudente, SP. Docente Centro Paula Souza - ETEC 032, Presidente Prudente, SP. ${ }^{2}$ UniCesumar, Programa de \\ Pós-Graduação, MBA em Agronegócio. ${ }^{3}$ Universidade Estadual Paulista - UNESP, FEIS/ Programa de Pós- \\ Graduação em Agronomia, Ilha Solteira, SP. Docente Centro Paula Souza - ETEC 032, Presidente Prudente, \\ SP. E-mail: levp@unoeste.br
}

\section{RESUMO}

A alface (Lactuca sativa L.) é a hortaliça folhosa mais consumida no Brasil. O presente trabalho teve por objetivo avaliar o efeito da adubação orgânica com esterco bovino, esterco de aves e mistura (bovino + aves) no desenvolvimento da cultura da alface. O experimento foi conduzido na horta da ETEC de Presidente Prudente. Utilizou-se um delineamento experimental inteiramente casualizado, contendo 4 tratamentos (adubações), com 10 repetições (plantas). Os tratamentos utilizados foram: T1 (15 kg de esterco bovino), T2 (5 Kg de esterco aves), T3 (2,5 Kg de esterco aves $+7,5 \mathrm{Kg}$ de esterco bovino) e T4 (testemunha). A adubação realizada com $5 \mathrm{~kg}$ de esterco de aves e a mistura de $2,5 \mathrm{~kg}$ de esterco de aves $+7,5 \mathrm{~kg}$ de esterco bovino promoveram o maior desenvolvimento agronômico da alface.

Palavras-chave: Agronegócio. Agroecologia. Sustentabilidade. Agricultura Familiar. Fertilidade.

\section{CATTLE MANURE OF USE AND POULTRY IN ORGANIC FERTILIZER LETTUCE AS PRACTICE AGROECOLOGICAL}

\begin{abstract}
Lettuce (Lactuca sativa L.) is the most widely consumed leafy vegetable in Brazil. This study aimed to evaluate the effect of organic fertilization with cattle manure, poultry manure and mix (beef + poultry) in the development of lettuce. The experiment was conducted in the garden of ETEC Presidente Prudente. We used a completely randomized design, with 4 treatments (fertilization), with 10 repetitions (plants). The treatments were: T1 (15 kg of manure), T2 (5 kg of dung birds), T3 ( $2.5 \mathrm{~kg}$ of dung birds $+7.5 \mathrm{~kg}$ of manure) and T4 (control). The fertilizer at $5 \mathrm{~kg}$ of poultry manure and a mixture of $2.5 \mathrm{~kg}$ of poultry manure $+7.5 \mathrm{~kg}$ of cattle manure promoted greater agronomic development of lettuce.
\end{abstract}

Keywords: Agribusiness. Agroecology. Sustainability. Family Farming. Fertility. 


\section{INTRODUÇÃO}

Principal responsável pela comida que chega às mesas das famílias brasileiras, a agricultura familiar responde por cerca de $70 \%$ dos alimentos consumidos em todo o País (MARTINS, 2001). 0 universo da agricultura familiar exibe grande capacidade produtiva, contribuindo de forma efetiva para o abastecimento do país, mesmo com o pouco acesso à terra, ao crédito e às inovações tecnológicas (INCRA/FAO, 2000).

Os temas saúde e qualidade de vida aparecem recorrentemente explorados não só no Brasil, mas em todo mundo. O intuito de uma prática diferenciada e sustentável na produção agropecuária brasileira é relacionar esses conceitos à agricultura orgânica e, mais especificamente, à agricultura familiar orgânica (AFO). Ressalta-se que no Brasil esses dois modelos são muito próximos, uma vez que cerca de $90 \%$ da produção orgânica no país é proveniente da Agricultura Familiar (AF) (MAPA, 2008).

Segundo Soares (2000), o conceito de agricultura e desenvolvimento rural sustentável pode ser resumido como um desenvolvimento sustentável que conserva o solo, a água, os recursos genéticos vegetais e animais, não degrada o meio ambiente e é tecnicamente apropriado, economicamente viável e socialmente aceitável. A produção agrícola sustentável, de acordo com GLIESSMAN (2000), é possuidora de base ecológica. Onde a produção seja "capaz de, perpetuamente, colher biomassa de um sistema, porque sua capacidade de se renovar ou ser renovado não é comprometida.

A agroecologia difundida dentro da agricultura familiar busca entender os agroecossitemas para produzir melhor e com menos impacto ambiental, social e econômico (ALTIERE, 2002). As formas de cultivo orgânico baseiam-se no uso de resíduos orgânicos, plantas na forma de adubos verdes e redução no revolvimento do solo, contrapondo o cultivo convencional que se utiliza de aplicações de agrotóxicos e adubações minerais solúveis. Para reduzir gastos com fertilizantes está sendo feita a introdução da adubação orgânica, pois uma das barreiras para a produção é o incremento e a manutenção da fertilidade do solo (KHATOUNIAN, 2001).

Atualmente, a preocupação com o ambiente e a qualidade de vida tem difundido amplamente as correntes de agricultura alternativa, dentre elas, a agricultura orgânica. Esse sistema de produção tem crescido continuamente, em função de uma demanda cada vez maior por produtos orgânicos (TRIVELLATO e FREITAS, 2003).

$\mathrm{O}$ aumento do custo dos fertilizantes minerais e a crescente poluição ambiental fazem do uso de resíduos orgânicos na agricultura uma opção atrativa do ponto de vista econômico, em razão da ciclagem de carbono e nutrientes (SILVA et al., 2010). Isto gera aumento na demanda por pesquisas para avaliar a viabilidade técnica e econômica dessa utilização (MELO et al., 2008).

A adubação orgânica com resíduo de origem animal (WHALEN et al., 2001; VAN KESSEL e REEVES, 2002; MENEZES e SALCEDO, 2007) é uma opção viável para manter os níveis de fertilidade, para reduzir os custos, aumentar a produtividade, melhorar as propriedades químicas e físicas do solo, diminuir a poluição e aumentar a eficiência de uso e qualidade nutricional nos sistemas de produção.

A adubação orgânica com utilização de resíduos gerados na própria unidade rural, ou nas proximidades, é uma prática muito comum na condução de lavouras de pequenos agricultores. Segundo Bayer e Mielniczuk (1999), em solos tropicais e subtropicais altamente intemperizados, a matéria orgânica tem grande importância no fornecimento de nutrientes às culturas, retenção de cátions, complexação de elementos tóxicos e de micronutrientes, estabilidade da estrutura, infiltração e retenção de água, aeração e atividade microbiana, constituindo-se em componente fundamental da sua capacidade produtiva.

A adubação orgânica com esterco animal e/ou compostos orgânicos tem sido amplamente utilizada na produção de alface, com o objetivo de reduzir as quantidades de fertilizantes químicos e melhorar as qualidades físicas, químicas e biológicas do solo (COSTA et al., 2011; STEINER et al., 
2011). Para a cultura da alface existe grande potencial de mercado entre os produtos orgânicos, visto que essa é consumida preferencialmente crua, na forma de saladas, e apresenta elevado teor de vitaminas e de sais minerais, indispensáveis na dieta humana. A alface geralmente apresenta boa resposta à adubação orgânica, no entanto, ela varia de acordo com a cultivar e a fonte de adubo utilizada (RICCl et al. 1995).

De acordo com Raij et al., (1996) a composição química média do esterco bovino fresco é a seguinte: 5 gramas por quilo de Nitrogênio; 2,6 gramas por quilo de fósforo; 6 gramas por quilo de potássio; 2 gramas por quilo de cálcio; 1 grama por quilo de magnésio; 1 grama por quilo de enxofre; 33 miligramas por quilo de zinco; 6 miligramas por quilo de cobre e 2 miligramas por quilo de níquel. Já para o esterco de aves fresco a composição média é: 14 gramas por quilo de Nitrogênio; 8 gramas por quilo de fósforo; 7 gramas por quilo de potássio; 23 gramas por quilo de cálcio; 5 gramas por quilo de magnésio; 2 gramas por quilo de enxofre; 138 miligramas por quilo de zinco; 14 miligramas por quilo de cobre e 2 miligramas por quilo de níquel.

O presente trabalho teve por objetivo avaliar o efeito da adubação orgânica com esterco bovino, esterco de aves e a mistura (bovino + aves) no desenvolvimento da cultura da alface. Visto que o uso de estercos para cultivo de hortaliças na agricultura familiar é uma prática muito comum que reduz custos de produção e pode agregar valor ao produto devido as características de seu sistema de cultivo.

\section{METODOLOGIA}

O experimento foi conduzido na horta da Escola Técnica Professor Dr. Antonio Eufrásio de Toledo (Colégio Agrícola) de Presidente Prudente/SP. O clima da região se classifica em Aw, com estação chuvosa no verão e estação seca no inverno. Foi utilizado um delineamento experimental inteiramente casualizado, contendo 4 tratamentos (adubações), com 10 repetições (plantas). Os tratamentos utilizados foram: T1 (15 kg de esterco bovino fresco por metro quadrado), T2 (5 Kg de esterco aves fresco por metro quadrado), T3 (2,5 $\mathrm{Kg}$ de esterco aves fresco $+7,5 \mathrm{Kg}$ de esterco bovino fresco por metro quadrado) e T4 (testemunha "sem adubação"). O esterco de aves utilizado no experimento foi o de galinha poedeira oriundo da criação existente na escola.

Por se tratar de resíduos que comumente são encontrados nas propriedades agrícolas e de fácil acesso ao pequeno produtor rural o esterco bovino e esterco de galinha foram escolhidos para realizar a execução do experimento. Como são dois produtos com composição química similar, porém em concentrações distintas principalmente quando comparado os teores de nitrogênio e fósforo, definiu-se que seria utilizado uma concentração maior de esterco bovino (três vezes) a concentração do esterco de galinha e uma mistura dos dois materiais utilizando metade da concentração de ambos. $O$ intuito é facilitar o entendimento e até mesmo o manejo do pequeno produtor quando o mesmo tiver a intenção de aplicar essas técnicas em sua propriedade.

Cada tratamento foi realizado incorporando os diferentes adubos a uma profundidade de 0-20 cm nos canteiros (parcelas), os canteiros possuíam 1 metro de largura por 1 metro de comprimento $\left(1 \mathrm{~m}^{2}\right)$.

No dia 24 de junho de 2015 realizou-se o preparo dos canteiros, instalação do sistema de irrigação por aspersão, distribuição dos adubos nos canteiros e incorporação. Passados trinta e três dias após a incorporação dos adubos realizou-se o transplantio das mudas de Alface Crespa Solaris com 20 dias de desenvolvimento, adotando-se o espaçamento de $25 \mathrm{~cm} \times 30 \mathrm{~cm}$ (planta e linha).

Após a realização do transplantio, foram distribuídos de forma homogênea sobre todos os canteiros cerca de $3 \mathrm{~cm}$ de palha oriunda de poda de jardim, com o objetivo de servir como cobertura vegetal para as plantas. A irrigação nos canteiros foi realizada diariamente em três períodos distintos do dia (9 horas, 13 horas e 16 horas), visando o fornecimento de água para as plantas nos períodos mais quentes do dia. 
Cinquenta e três dias após o desenvolvimento da cultura foram coletadas amostras de cada tratamento e levadas para o laboratório para a realização das análises de avaliação do desempenho agronômico, sendo estas: comprimento da parte aérea, diâmetro da parte aérea, número de folhas e massa fresca da parte aérea. 0 comprimento e diâmetro da parte aérea foi realizado utilizando uma fita métrica aprovada e homologada pelo Inmetro (Instituto Nacional de Metrologia, Qualidade e Tecnologia). Para a determinação da massa fresca da parte aérea foi utilizado balança Semi Analítica.

Todos os dados foram submetidos à análise de variância (ANOVA, $p<0,05$ ) e ao teste de comparação de médias Scott-Knott $(p<0,05)$, segundo Silva (2011).

\section{RESULTADOS}

A partir dos resultados expressos na tabela 01, observa-se que as fontes utilizadas de adubação orgânica obtiveram melhores respostas em relação as variáveis analisadas (desempenho agronômico da alface) quando comparado com o tratamento testemunha (sem adubação).

Tabela 01. Resultados de análises estatísticas das variáveis analisadas "Massa Fresca da Parte Aérea (MFPA), Diâmetro da Planta (DP), Altura da Planta (AP) e Número de Folhas (NF) " em relação as fontes de adubação utilizadas no experimento.

\begin{tabular}{lcccc}
\hline TRATAMENTOS & MFPA $(\mathrm{g})$ & DP $(\mathrm{cm})$ & AP $(\mathrm{cm})$ & NF \\
\hline T1 (Esterco bovino) & $448,5 \mathrm{a}$ & $0,995 \mathrm{~b}$ & $29,0 \mathrm{a}$ & $32,0 \mathrm{a}$ \\
T2 (Esterco aves) & $537,0 \mathrm{a}$ & $111,7 \mathrm{a}$ & $30,1 \mathrm{a}$ & $32,9 \mathrm{a}$ \\
T3 (Esterco bovino + aves) & $439,0 \mathrm{a}$ & $113,5 \mathrm{a}$ & $29,2 \mathrm{a}$ & $31,8 \mathrm{a}$ \\
T4 (Testemunha) & $71,0 \mathrm{~b}$ & $0,574 \mathrm{c}$ & $15,6 \mathrm{~b}$ & $17,9 \mathrm{~b}$ \\
\hline Média Geral & 373,9 & 56,69 & 25,9 & 28,7 \\
\hline CV (\%) & 26,42 & 9,27 & 5,71 & 13,31 \\
\hline
\end{tabular}

Médias seguidas por letras iguais na coluna não diferem entre si pelo teste de Scott-Knott a 5\%.

\section{DISCUSSÃO}

De acordo com Silva et al. (2011), a adubação orgânica não só incrementa a produtividade, mas também produz plantas com características qualitativas melhores que as cultivadas exclusivamente com adubos minerais podendo, portanto, exercer influência sobre a qualidade nutricional da alface. Embora seja recomendada a aplicação dos estercos com a menor antecedência possível da época do plantio, o esterco fresco deve ser incorporado bem antes para evitar prejuízos às plantas devido à concorrência pelo $\mathrm{N}$ disponível (COSTA, 1994).

Entre os adubos orgânicos utilizados há maior destaque para os tratamentos 2 (Esterco de aves) e 3 (Esterco bovino + aves), os mesmos alcançaram resultados mais significativos em todas as variáveis do experimento. 0 tratamento 3 (Esterco bovino) obteve resultado inferior para a variável diâmetro da alface, fator esse que pode ter influência na comercialização do produto. Como já era esperado os resultados inferiores de desempenho agronômico da alface foram encontrados no tratamento 4 (testemunha) comprovando nesse caso que a adubação orgânica utilizada no experimento, independentemente do tipo, influenciou positivamente no desenvolvimento da cultura e promoveu maior produção de massa fresca, diâmetro e altura da alface quando comparada com a adubação a testemunha. Esses resultados condizem com os obtidos por Peixoto Filho et al. (2013), no qual os autores concluem que em todas as variáveis estudadas no experimento a testemunha foi o tratamento que apresentou valores inferiores por não ter recebido nutrientes via fertilização e a melhor produtividade em $\mathrm{kg} \mathrm{ha}^{-1}$ de alface foi obtida com a utilização de esterco de frango. 
Deve-se ressaltar que os adubos orgânicos ficaram incorporados no solo por um período de trinta e três dias, o que pode influenciar na diminuição dos valores de nitrogênio presentes nos estercos devido aos processos de lixiviação e volatilização, reduzindo assim a quantidade do elemento disponível para as plantas quando realizado o transplantio da alface. Nos resíduos orgânicos, o N apresenta-se, na maioria dos casos, em maior proporção na forma amoniacal $\left(\mathrm{NH}^{+}\right.$ + NH3), podendo chegar a 70\% do $\mathrm{N}$ total (SCHERER et al., 1996). Nessa forma, o $\mathrm{N}$ está suscetível a perdas, principalmente por volatilização da amônia, tanto nos locais de armazenamento dos dejetos (Sommer et al., 1993) como após a sua aplicação no campo (ROCHETTE et al., 2001).

A adubação orgânica segundo Leite et al., (2003) aumenta os estoques de carbono orgânico e $\mathrm{N}$ total no solo, em relação aos sistemas de produção com adubação mineral ou mesmo sem adubação, o que posiciona como uma estratégia de manejo importante à conservação da fertilidade do solo. A incorporação de material orgânico no solo, além de fornecer nutrientes como N, P, K e S, influência as propriedades físicas do solo, reduzindo a densidade aparente, formando agregados, melhorando a aeração e a capacidade de armazenamento de água (KIEHL, 1985). Segundo o autor, os adubos orgânicos têm, também, efeito sobre o poder tampão do solo ao manter o pH quando há mudanças bruscas no meio, além de favorecer a troca catiônica, complexar e solubilizar alguns metais tóxicos às plantas e ter influência na temperatura do solo. Outros efeitos, segundo Costa (1994), são o de favorecer o enraizamento, diminuir os efeitos tóxicos do Al e aumentar a atividade microbiana do solo.

Contudo, o efeito benéfico da utilização de material orgânico na agricultura tem sido amplamente difundido. Dessa forma culturas adubadas com composto orgânico, normalmente apresentam plantas com nutrição mais equilibrada e com melhor desenvolvimento do que aquelas adubadas somente com fertilizantes minerais (OLIVEIRA e DANTAS, 1995).

\section{CONCLUSÃO}

O uso da adubação com esterco de aves e a mistura de esterco de bovino + esterco de aves promoveram o maior desenvolvimento da cultura do alface.

\section{REFERÊNCIAS}

ALTIERI, M., Agroecologia: bases científicas para uma agricultura sustentável. Guaíba, 2002. $592 p$.

BAYER, C.; MIELNICZUK, J. Dinâmica e função da matéria orgânica. In: SANTOS, G. de A.; CAMARGO, F.A. de O. (Ed.). Fundamentos da matéria orgânica do solo: ecossistemas tropicais e subtropicais. Porto Alegre: Gênesis, 1999. p.9-26.

COSTA, M. B. B. da. Adubação orgânica: nova síntese e novo caminho para a agricultura. São Paulo: Ícone, 1994. 102p.

COSTA, M. S. S. M.; PIVETTA, L.A.; COSTA, L.A.M.; PIVETTA, L.G.; CASTOLDI, G.; STEINER, F. Atributos físicos do solo e produtividade do milho sob sistemas de manejo e adubações. Revista Brasileira de Engenharia Agrícola e Ambiental, Campina Grande, v. 15, n. 8, p. 810-815, ago. 2011.

GLIESSMAN, Stephen R. Agroecologia: processos ecológicos em agricultura sustentável. Porto Alegre: Ed. Universidade/UFRGS, 2000.

INCRA. Novo Retrato da Agricultura Familiar: 0 Brasil Redescoberto. Ministério do Desenvolvimento Agrário, Brasília, Fevereiro de 2000. 
KIEHL, E.J. Fertilizantes orgânicos. São Paulo: Ceres, 1985. 492p

LEITE, L.F.C.; MENDONÇA, E.S.; NEVES, J.C.L.; MACHADO, P.L.O.A.; GALVÃO, J. C.C. Estoques totais de carbono orgânico e seus compartimentos em Argissolo sob floresta e sob milho cultivado com adubação mineral e orgânica. Revista Brasileira de Ciência do Solo, Viçosa, v.27, n.5, p.821-832, 2003.

KHATOUNIAN, C. A. A reconstituição ecológica da agricultura. Botucatu: Agroecológica, 2001. $348 p$.

MAPA. MINISTÉRIO DE AGRICULTURA, PECUÁRIA E ABASTECIMENTO. MAPA. Produção e comércio de orgânicos têm novas regras. 2008. Disponível em: <http://www.agricultura.gov.br/> Acesso em 02 Jan. 2016.

MARTINS, J.de S. Ímpares sociais e políticos em relação à reforma agrária e a agricultura familiar no Brasil. Santiago Chile, 2001.

MELO, L. C. A.; SILVA, C. A.; DIAS, B. de O. Caracterização da matriz orgânica de resíduos de origens diversificadas. Revista Brasileira de Ciência do Solo, v.32, p.101-110, 2008. https://doi.org/10.1590/S0100-06832008000100010

MENEZES, R.S.C.; SALCEDO, I.H. Mineralização de N após incorporação de adubos orgânicos em um Neossolo Regolítico cultivado com milho. '1, v.11, n.4, p.361- 367, 2007.

OLIVEIRA, A.M.G.; DANTAS, J.L.L. Composto orgânico. Cruz das Almas: Embrapa - CNPMF, 1995. 12p. (Embrapa - CNPMF. Circular Técnico, 23).

PEIXOTO FILHO, J. U.; FREIRE, M. B. G. dos S.; FREIRE, F. J.; MIRANDA, M. F. A.; PESSOA, L. G. M.; KAMIMURA, K. M. Produtividade de alface com doses de esterco de frango, bovino e ovino em cultivos sucessivos. Revista Brasileira de Engenharia Agrícola e Ambiental. vol.17, n.4, pp.419424, 2013. https://doi.org/10.1590/S1415-43662013000400010

RAlJ, B. van et al. (Ed.). Recomendações de adubação e calagem para o Estado de São Paulo. 2.ed. Campinas: Instituto Agronômico, 1996. (IAC. Boletim Técnico, 100).

RICCI, M. S. F.; CASALI, V. W.; CARDOSO, A. A,; RUIZ, H. A. 1995. Teores de nutrientes em duas cultivares de alface adubadas com composto orgânico. Pesquisa Agropecuária Brasileira 30: 10351039. https://doi.org/10.4141/S00-044

ROCHETTE, P.; CHANTIGNY, M. H.; ANGERS, D. A.; BERTRAND, N.; CÔTÉ, D. Ammonia volatilization and soil nitrogen dynamics following fall application of pig slurry on canola crop residues. Canadian Journal of Soil Science, Ottawa, v. 81, n. 3, p. 515-523, 2001.

Silva, E. M. N. C. P.; FerreirA, R. L. F.; ARAúJo Neto S. E.;TAVella, L. B.; SOlino, A. J. S. Qualidade de alface crespa cultivada em sistema orgânico, convencional e hidropônico. Horticultura Brasileira, v.29, p.242-245, 2011. $\underline{\text { https://doi.org/10.1590/S0102- }}$ $\underline{05362011000200019}$ 
SILVA, F. A. M.; VILAS-BOAS, R. L.; SILVA, R. B. da. Resposta da alface à adubação nitrogenada com diferentes compostos orgânicos em dois ciclos sucessivos. Acta Scientiarum Agronomy, v.32, p.131-137, 2010. https://doi.org/10.4025/actasciagron.v32i1.1340

SILVA, F. de A. S. Assistat. Versão 7.6 beta (2011). Disponível em http://www.assistat.com/indexp.html.

SOARES. A. C. A multifuncionalidade da agricultura familiar. Proposta $\mathrm{nr}$ 87. Rio de janeiro: Action Aid Brasil.dez//fev 2000/2001.

SCHERER, E. E.; AITA, C.; BALDISSERA, I. T. Avaliação da qualidade do esterco líquido de suínos da região oeste catarinense para fins de utilização como fertilizante. Florianópolis: Epagri, 1996. 46 p. (Boletim Técnico, 79).

STEINER, F.; COSTA, M.S.S. de M.; COSTA, L.A. de M.; PIVETTA, L.A.; CASTOLDI, G. Atributos químicos do solo em diferentes sistemas de culturas e fontes de adubação. Global Science and Technology, Rio Verde, v. 4, n. 1, p. 16-27, jan./abr. 2011.

VAN KESSEL, J.S.; REEVES, J.B. Nitrogen mineralization potential of dairy manures and its relationship to composition. Biology and Fertility of Soils, v.36, p.118-123, 2002. https://doi.org/10.1007/s00374-002-0516-y

WHALEN, J.K.; CHANG, C.; OLSON, B.M. Nitrogen and phosphorus mineralization potentials of soils receiving repeated annual cattle manure applications. Biology and Fertility of Soils, v.34, n.5, p.334-341, 2001. https://doi.org/10.1007/s003740100416 